\title{
A Systematic Review of Synthetic Biology - A New Era in Biopharmaceutical Drug Development
}

\author{
Başak Kandemir ${ }^{1,2 \phi^{*}}$, Oya Arı Uyar ${ }^{2 \theta^{*}}$, E Damla Arısan ${ }^{1,3}$ and Işıl Aksan Kurnaz ${ }^{1,2 *}$ \\ ${ }^{1}$ Gebze Technical University, Biotechnology Institute, 41400 Gebze, Kocaeli, Turkey \\ ${ }^{2}$ BIOM Biotech LLC, TÜBİTAK Marmara Technokent, 41470, Gebze, Kocaeli, Turkey \\ ${ }^{3}$ DAPGenomics LLC, Ylldız Teknik Technopark, Incubator, Istanbul-Turkey \\ *Authors have contributed equally to this manuscript. \\ $\phi$ Present address: Baskent University, Department of Molecular Biology and Genetics, Ankara \\ ${ }^{\theta}$ Present address: TUBITAK Marmara Research Center (MAM), Gebze Kocaeli \\ *Corresponding author: Ișıl Aksan Kurnaz, Gebze Technical University, Institute of Biotechnology, Gebze Kocaeli Turkey
}

\section{ARTICLE INFO}

Received: 絊 July 15, 2020

Published: 幽 July 24, 2020

Citation: Başak Kandemir, Oya Arı Uyar, E Damla Arısan, Işıl Aksan Kurnaz. A Systematic Review of Synthetic Biology - A New Era in Biopharmaceutical Drug Development. Biomed J Sci \& Tech Res 29(1)-2020. BJSTR. MS.ID.004753.

Keywords: Biotechnology; Recombinant DNA technology; Biopharmaceuticals; Synthetic biology

\section{ABSTRACT}

Although biotechnology dates back to ancient times, biotechnology as we know it started with the scientific advances elucidating fermentation, microorganisms, protein, and DNA biochemistry. Today, modern biotechnology that uses recombinant DNA technology as its primary tool is undergoing transformation into synthetic biology. Nobel Prize in Chemistry 2018 was awarded in part to Prof. Frances Arnold, for her work on enzyme evolution, who is also the founder of a synthetic biology company. Synthetic biology was first coined in 1990s and was initiated by engineers who have dreamed of joining engineering principles with the concept of microbial cell factories, parallel to the genomic era and the birth of systems biology. It is built on the notion of modifying and improving whole new metabolic pathways, not only proteins or enzymes. Recent advances in genome editing tools, expansion of non-natural amino acid incorporation, addition of new "letters" to the DNA alphabet and a large spectrum of new developments push the boundaries of our imaginations. Many funding and investment schemes in our country are currently focusing on "modern" biotechnology and bioengineering, but without further ado we must urgently focus on tomorrow's technology, synthetic biology.

\section{Introduction}

\section{Biotechnology: A Historical Perspective}

Biotechnology is a technology that strategically aims to convert raw materials into more useful products with the help of organisms. This definition of biotechnology relies mainly on the early understanding of fermentation in the 1900s, which put forward the importance of the microbial fermentation technology on the purification and production of a number of organic molecules at industrial level [1]. This strategic movement in industry led to production of vital primary metabolites such as lactose, ethanol, amino acids, antibiotics such as penicillin, which were produced and purified in large quantities. In addition, different enzymes, or proteins, which possess commercial value, were extracted using increased knowledge at industrial utilization of biotechnologybased tools [2]. The successful industrial progress based on biotechnology was one of the important revolutions for bio-based economies, however biotechnology as a term was not coined until 1919.

Modern biotechnology became a more powerful tool with the help of recombinant DNA technology that was developed in late 1970s, which enabled researchers to express genes from one organism in another host organism. In particular, technologies that enable sequencing and altering the genomes of microbial organisms promised more valuable products at different industry sectors such as pharmacy, food, and agriculture [3].

All these efforts not only increased the knowhow about biotechnological product development process but also significantly decreased cost of production, bypassing the challenges to obtain purified and large-scale bio-based products using earlier 
technologies. Therefore, modern biotechnology can be accepted as the second revolution in industrial and medical biotechnology. Towards the 1990s, the genetics of microorganisms were modified with the use of recombinant DNA technology, which enabled the protein coding region obtained from any organism to be produced in the desired organism as a result of cloning into a carrier DNA vector, thereby enabling the production of human proteins in the host organism (e.g. bacteria) [4]. During this period, many biotechnology companies, such as Genentech that commercialized the recombinant human growth hormone, were founded, and commercialization of biotechnology started [5] (Figure 1). Today, with the increase of biotechnology, not only medicine and pharmaceutical industry, but also agriculture and environmental industries are ever expanding, for instance global biotechnology crop areas increased to 4.7 million hectares in 2017, and an economic gain of US \$ 186.1 billion was achieved between 19962016 worldwide [6-8].

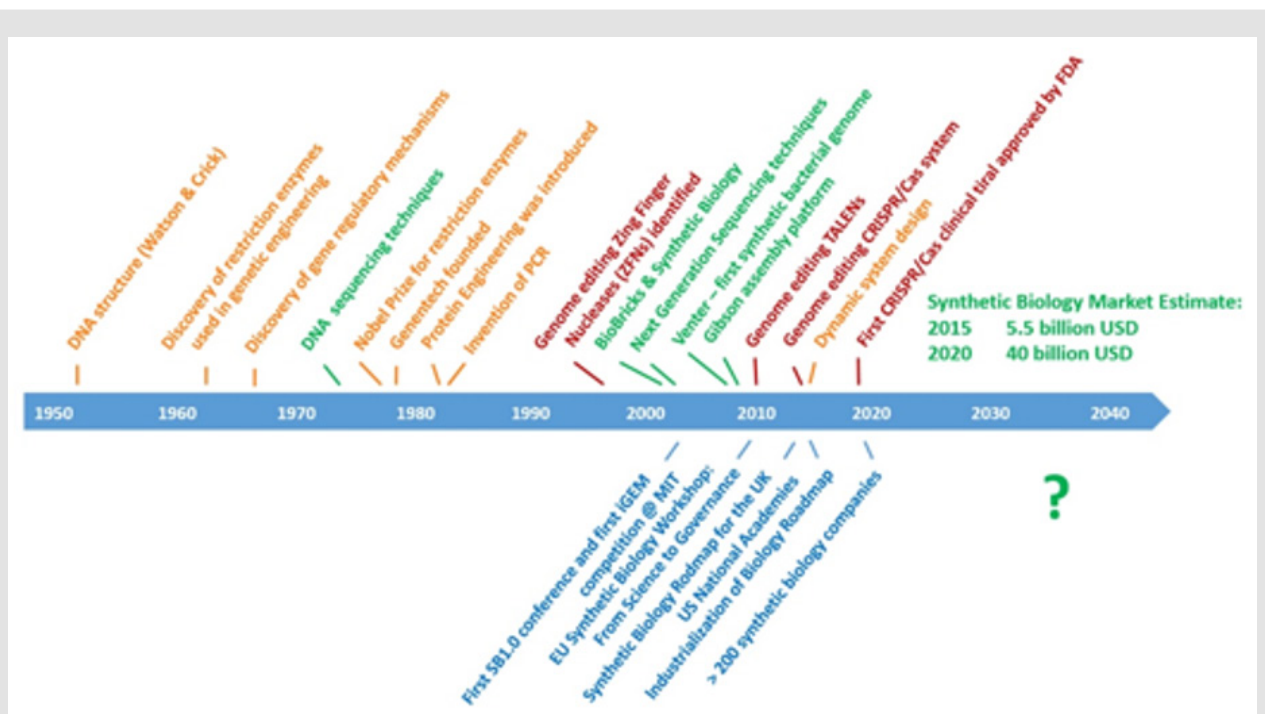

Figure 1: Timeline of advanced-technological insights of biotechnology, genomics, and synthetic biology.

\section{Synthetic Biology Era}

With the completion of the human genome project in the early 2000s, synthetic biology underlined the possible third revolution of industrial and medical biotechnology as a game changer, which allowed the production of novel molecules in living organisms and also manipulation of organisms as live biosensors. Of course, this required a series of technological advances such as Next Generation Sequencing, omics technologies, and genome editing techniques (Figure 1). Protein engineering, enzyme engineering and metabolic engineering fields can be assumed as predecessors of synthetic biology - enabling researchers to alter the sequence and function of proteins or enzymes, or indeed entire metabolic pathways, paved the way to a more flexible and unhindered Lego brick-based attitude of synthetic biology that followed $[9,10]$.

While enzyme engineering was first performed with immobilization methods and complemented with detailed kinetic studies in 1980s, the use of recombinant DNA technology to optimize proteins or enzymes for particular desired phenotypes or properties became mainstream in 1990s, mainly relying on technologies such as random or site-directed mutagenesis, phagedisplay and other [11,12]. Nobel Laureate Prof Frances Arnold is most renowned for her work on directed evolution of enzymes for industrial production of metabolites and commercial application of such catalysts and their use in this field have become possible
$[13,14]$. These all efforts might be critical in the restoration of biodiversity for a sustainable blue planet. , systems biology can be critical approach with its novel approach and application strategies for the sustainability of bioresources and restored the required biodiversity for a live planet.

\section{Biopharmaceuticals and Synthetic Biology}

Recombinant proteins and enzymes as well as antibodies and vaccines are important biopharmaceuticals. Recombinant somatostatin and recombinant human insulin were among the first recombinant therapeutics to be expressed in bacteria and commercialized by Genentech [15]. Recombinant therapeutic enzymes have also been commercialized since the 1960s, for example in the early 1990s the human tissue plasminogen activator alteplase enzyme (commercialized under the name Aktivaz) was approved by the FDA and used in the treatment of clot-induced heart attacks, and recombinant Adenosine Deaminase (ADA) was approved for ADA deficiencies (Table 1) [17] (ADA enzyme has also been used in the gene therapy of Severe Combined Immunodeficiency (SCID), a pioneer in gene therapy trials $[18,19]$. Extracting such bio valuables from natural producers (such as bacteria, human cells, yeast, or plants) present challenges, the most important being limited availability of such bioresources, and the threat of industrial harvesting or cultivation on biodiversity. Recombinant cells, on the other hand, show higher performance as 
bio factories in production of the desired product, in theory without the need for collecting from nature (such as trypsin from pancreas etc) [20]. In 2018, FDA has approved 59 novel drugs, including many monoclonal antibodies, hormones, or RNAi drugs [21,22].

Some recombinant biotechnological drugs tend to be open to engineering techniques to improve performance and new functionality, developed using traditional methods, and such recombinant proteins appear in many applications made to the American Food and Drug Administration (US Food and Drug Administration, FDA) between 2013 and 2018 (Table 1) [23,24]. In countries such as Turkey, due to the high cost of generating a biopharmaceutical or biological drug from research to market

approval, many biotechnology companies prefer to focus on biosimilars. Unlike a generic drug, which is chemically identical to the original branded drug, biosimilars are "highly similar" to the original biological drug, and since these are produced in host organisms as described above, they may have minor differences in active ingredients while no significant clinical differences [25]. However, since the tests required to show such high level "similarities" are numerous and complex, biosimilars are only 15$20 \%$ cheaper than the original drug, as opposed to generics cost almost 40 to $50 \%$ less than the original drug. FDA has approved 12 biosimilars, including Filgrastim and Bevacizumab, and has also rejected quite a number of applications, which adds to the overall cost of biosimilar development and production [26].

Table 1: Some of the FDA approved therapeutic proteins between 2013-2018.

\begin{tabular}{|c|c|c|c|}
\hline Application year & The name of the drug & Class Definition \\
\hline 2013 & $\begin{array}{c}\text { Coagulation factor IX } \\
\text { Recombinant, human }\end{array}$ & Coagulation factor \\
\hline 2014 & C1 esterase inhibitor Recombinant & Plasma protein \\
\hline 2015 & von Willebrand factor Recombinant & Plasma protein \\
\hline 2016 & Antihemophilic factor Recombinant & Coagulation factor \\
\hline 2018 & Cenegermin & Nerve Growth Factor & hematology \\
\hline 2018 & Elapegademase & Recombinant adenosine deaminase & Adenosine deaminase deficiency \\
\hline
\end{tabular}

The first target in biopharmaceutical sector is to replace the function of a missing protein or enzyme with biological drugs or biosimilars, as explained above. However, it is possible not only to replace the missing function, but also to improve it. Protein and enzyme engineering aim to make the desired changes in the amino acid sequences of proteins and enzymes by site directed mutagenesis to improve properties such as ligand binding or catalytic activity. Therefore, recombinant proteins that can be designed on demand have been a good option for the pharmaceutical industry as they allow rapid therapeutic protein production. Such biological drugs are called Biobetters, which are improved versions of the recombinant drug, usually improved with respect to half-life, efficacy, aggregation problems or adverse effects [27]. Usually, development cost of a Biobetters is the same as or higher than developing a new biological drug, yet even the recombinant alterations to the original biologics have currently been limited, such as fusion of albumin or other proteins to increase half-life, addition of peptide sequences to enhance tissue targeting and efficacy. Several biobetters have gained FDA approvals, including trastuzumab biobetter or filgrstim biobetter, which have improved efficacy or improved dosing frequency, respectively [28-30].

In fact, biotechnology has been trying to keep up with many technological advances and innovations in recent years - genetic and molecular technologies such as next-generation sequencing, high-scale screening technologies, single-cell omics studies have significantly accelerated drug target discovery, as well as CRISPR/ Cas, which is described more broadly below. Developments such as making genomic editing tools very effective and easy to use, recombinant DNA technology and facilitating genomic editing DIY (do-it-yourself) kits so that they can be made at home by ordering from online sites also push biotechnology in different directions [31].

\section{Synthetic Biology}

In the late 1990s, the field of synthetic biology was built on the use of cells, proteins, genes, and promoters to design and manufacture entirely new circuits and systems not found in nature, with the idea that engineering concepts could be applied to biological systems [32]. Synthetic biology includes engineering applications with biological systems that have structures and functions that are not found in nature to process information, manipulate chemicals, generate energy, protect the cell environment, and improve human health, and enables us to understand disease mechanisms and develop new diagnostic tools [33]. Methods based on synthetic biology enable the design of inexpensive and new strategies for the treatment of cancer, immune diseases, metabolic disorders, and infectious diseases. In fact, it is possible to base its debut on DNA sequencing technologies in the late 1970s, but it was the first time it became widespread and consolidated by Bio Bricks systems commercializing the standardization processes with the trackdevice-chassis approach, and it became the world after announcing J Craig Venter's first synthetic bacterial genome.

Synthetic biology briefly works on the principle of combining the mentioned bio Bricks-like "standardized" parts with desired combinations like the same lego toys and converting them into "output" by processing logic gates (input / output, I / 0) (Figure 
2). Synthetic biology, which was previously used to create more biosensor systems, is now being used to produce the desired biotechnological product with more efficient processes and less costmore product principle. Because with this method, the production of the desired biotechnological product ("output") can be produced with the desired stimulus ("input") in the desired organism by designing completely original and often non-natural circuits and pathways. Knowledge from synthetic biology is transferred to generation of different product types such as environmental biosensors, which is used as diagnostic or monitorization of field studies. In a similar understanding the developed biosensors are used in in vivo systems to diagnose or track the diseases. One of the promising developments is the generation of the novel nanobots, which enter the circulation system to diagnose and report tumorigenesis real-time.

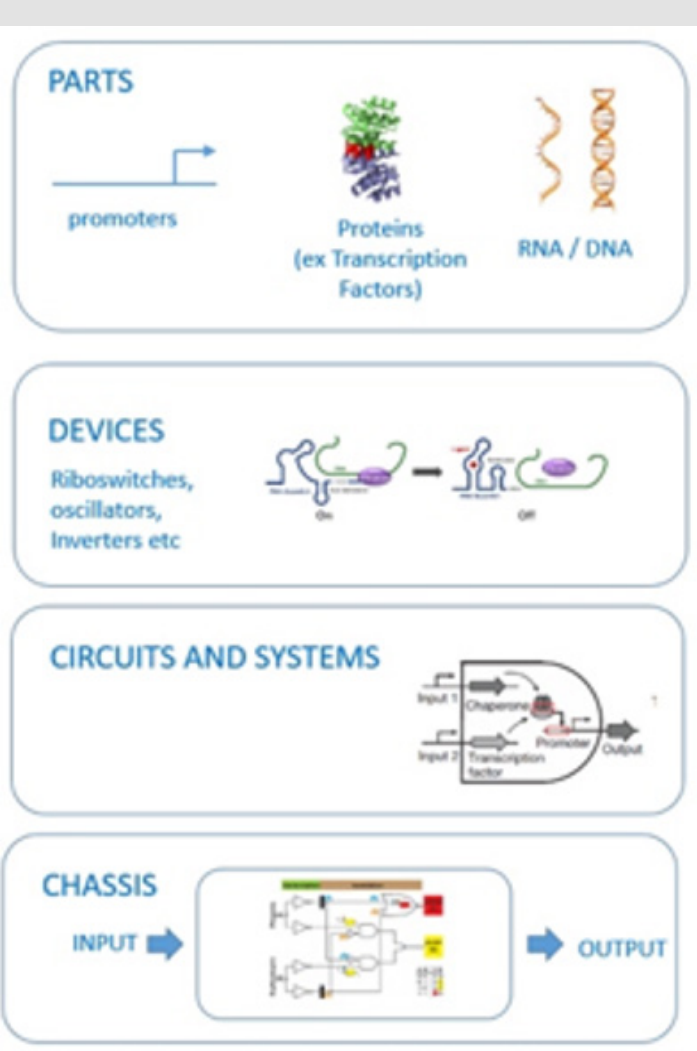

Figure 2: Summary of part, circuit, system, and chassis relationships in synthetic biology.

Biotechnology does not only consist of protein, enzyme, and antibody production, but include various products and services such as cellular therapies, gene therapy, tissue engineering, and 3D bioprinting. However, as we have tried to emphasize, these treatments are aimed at providing function to dysfunctional cells or tissues in order to compensate for lost functions for the treatment of the disease. However, the target of synthetic biology researches may be mentioned by introducing new functions that are not found in nature, for example, bacterial sensors that mark the tumor tissue, and the therapeutic approaches that release insulin by detecting the amount of glucose in the blood. The first example of the use of synthetic biology in drug production is the design of a new synthetic circuit in Saccharomyces cerevisiae, a yeast of plant origin and taxol, and the design of new synthetic circuits that increase isoprenoid production efficiency.

Another development in biotechnology, which is proceeding in parallel with these developments and whose name we frequently hear in the media, is genome editing or editing method. The development of genome-regulating zinc finger nuclease was in the early 2000s, limited by only some research laboratories since it was very slow and inefficient, with the TALEN systems first and then the CRISPR / Cas9 system that we often hear today. has gained popularity. New generations of CRISPR systems have entered our lives in a way that is much more effective and easier to use and started to appear in clinical therapeutic trials with FDA approval. The FDA, which allowed CRISPR trial for sickle cell anemia disease, withdrew this approval in May 2018, and in December 2018 approved it for a trial for hereditary childhood blindness. It is certain that developments in this field and regulation processes in therapeutic use will carry synthetic biology to a different dimension. Transformation of biosynthetic pathways and systems in microorganisms through genetic manipulation made it possible to investigate the extensive chemistry of natural product derivatives. Today, synthetic cells are not only used as biofabrics, but are also used as cell-based screening platforms for both target-based and phenotypic-based approaches. Genetic circuits designed in synthetic cells are also used to decipher disease mechanisms of drug action mechanisms and to study cellcell communication within the bacterial consortium.

\section{Future Trends}

Research on synthetic biology is encouraged by different funding agencies to increase knowledge and prospective products in the U.S. and the UK. The wide acceptance of personalized medicine by the pharmaceutical industry and healthcare professionals is increasing. Research is conducted on synthetic biology in more than 300 locations in the USA and Europe. These include 70 companies (60 in the USA and 10 in Europe) and 125 universities (95 in the USA and 30 in Europe); The rest are research institutes and laboratories. This number has been increasing in the past few years and is expected to continue increasing in the coming years. In the U.S., when all subdomains consider the total domestic income from biotechnology products to be almost $\$ 325$ billion, the strong interest of private funds as well as governments is appreciated (see "Preparation for Future Biotechnology Products"). In September 2018, a new \$4.5 million Synthetic Biology Initiative was announced by the Australian Industrialized Biotechnology Alliance Initiative (which itself has a total investment of $\$ 20$ million) to sustain sustainable, export-oriented biotechnology. The investment made in more than 60 synthetic biology startups in 2016 has exceeded 1 billion USD in total (https://www.cbinsights.com/research/ synthetic-biology-startup-market-map/). 
Due to precisely these investments and the way technology is advancing, legislative studies on synthetic biology have been going on for many years - FDA's regulatory changes for synthetic biology products began in the late 1990s. The European Commission has also published opinion reports on synthetic biology practices and products in different sectors. These include recombinant DNAderived protein or peptide products and products combined with monoclonal antibody, as well as diagnostic products. Most of the ethical and human health regulations have been defined mostly through Genetically Modified Organisms (GMOs) and food and agricultural products. It is certain that intensive ethical studies of diagnostic, therapeutic or biotechnological drug approaches and products based on synthetic biology such as design viruses, microorganisms and cells are required. As a matter of fact, the investments are gradually emerging as products: In the UK, the DNA codes of the E. coli bacteria were completely rewritten by human beings, that is, synthetic DNA. Artificial but viable E. coli bacteria are thought to be useful for future use in the pharmaceutical industry.

\section{Synthetic Biology Market}

This review, while we are approaching 2020, biotechnology focuses on "synthetic biology" in the world while intensive biotechnological drug investments are made in our country. The synthetic biology market, which was 5.5 billion USD in 2015, is estimated to be 40 billion USD in 2020. The aim of this review is to emphasize the importance of this new era in biotechnology and to express our obligation to take our place in this market. Right now, we are all trying to transform industry with all components for a fully digital future. Fourth industrial revolution (4IR) needs to clarify a number of issues about biotechnology and its existing power in bio-based economies. Synthetic biology provides a new tool for industrial leaders to play Lego-based DNA recombination approach to create novel products that meet public need. Increased understanding about big data in biological sciences promotes the possible combinations by this way. 4IR starts with Internet of Things (IoT), which allows development of digitalization of goods for advanced products in different sectors. It is assumed that we will be an active consumer of 30 billion devices, which is equipped with sensors and processors by the end of 2025. 4IR is critical to emphasize the potential role of biotechnology in industry.

It is well known that over excess production leads to real world problems such as waste from industrial processes, which are not controlled in a regulatory way, generation of large amounts of greenhouse gases, micro and macro pollutants with high nondegradable properties etc. Here the main role of biotechnology is to solve all these unwanted outcomes of classical industry in the near future. The economic value of health care is worth about 81.7 trillion USD and for this reason it is the one of the leading industries worldwide. Therefore, health biotechnology with the power of synthetic biology will lead the future perspective of the healthcare industry. Recently, quite a number of biotechnology fund and investment opportunities in Turkey, especially in the case focused on pharmaceutical and biomedical devices. Synthetic biology market is calculated to be 5.5 billion USD in 2015, and it is expected to be 40 billion USD in 2020. Therefore, although investments in biotechnological medicine are late but positive steps, it is time to focus not only on today's technology but also on tomorrow's technology, considering the investments and market projections abroad in the field of synthetic biology. Designing innovative, accelerating biotechnology collaboration centers or platforms has been a requirement to mobilize existing infrastructures.

\section{Acknowledgement}

We would like to thank the TÜBITAK 1512 program for supporting the establishment of the BIOM Biotechnology Company.

\section{Funding}

This study conducted in part in BIOM LLC founded with 1512 techno innovation grant by TUBITAK.

\section{Conflict of Interest}

The authors declare no conflict of interest.

\section{References}

1. Adamu S, Koki A, Adamu S, Musa A, Abdullahi A (2016) Biotechnology as a Cradle of Scientific Development: A Review on Historical Perspective. J Adv Biol Biotechnol 10(4): 1-12.

2. Adrio JL, Demain AL (2010) Recombinant organisms for production of industrial products. Bioeng Bugs 1(2): 116-131.

3. Agbogbo FK, Ecker DM, Farrand A, Han K, Khoury A, et al. (2019) Current perspectives on biosimilars. J Ind Microbiol Biotech 46(9-10): 1297 1311.

4. Arnold FH (2018) Directed Evolution: Bringing New Chemistry to Life. Angew Chemie Int Ed 57(16): 4143-4148.

5. Brannigan JA, Wilkinson AJ (2002) Protein engineering 20 years on. Nat Rev Mol Cell Biol 3(12): 964-970.

6. Cameron DE, Bashor CJ, Collins JJ (2014) A brief history of synthetic biology. Nat Rev Microbiol 12(5): 381-390.

7. Carroll D (2017) Genome editing: Past, present, and future. Yale J Biol Med 90(4): 653-659.

8. Chen Z, Wang J, Sun W, Archibong E, Kahkoska AR, et al. (2018) Synthetic beta cells for fusion-mediated dynamic insulin secretion. Nat Chem Biol 14(1): 86-93.

9. Cobb RE, Chao R, Zhao H (2013) Directed evolution: Past, present, and future. AIChE J 59(5): 1432-1440.

10. Courbet A, Renard E, Molina F (2016) Bringing next-generation diagnostics to the clinic through synthetic biology. EMBO Mol Med 8(9): 987-991.

11. EC SCHER (2014) Opinion on Synthetic Biology I - Definition. Scientific Comm. Emerg. New. Identified Heal. Risks (SCHENIHR), Scientific Comm. Consum. Safety (SCCS), Scientific Comm. Heal. Environ. Risks (SCHER) Report.

12. Fredens J, Wang K, De la Torre D, Funke LFH, Robertson WE, et al. (2019) Total synthesis of Escherichia coli with a recoded genome. Nature 569: 514-518.

13. ISAAA (2017) Global Status of Commercialized Biotech/GM Crops in 2017: Biotech Crop Adoption Surges as Economic Benefits Accumulate in 22 Years. 
14. Jain KK (2013) Synthetic biology and personalized medicine. Med Princ Pract 22(3): 209-219.

15. James C (2014) Brief 49 Global status of Commercialized biotech / GM Crops: 2014. Int Serv Acquis Agri-biotech Appl (ISAAA).

16. Mody CCM (2012) Genentech: The Beginnings of Biotech (review). Bull Hist Med 86(1): 145-146.

17. Mullard A (2019) 2018 FDA drug approvals. Nat Rev Drug Discov 18: 85-89.

18. Mullard A (2020) 2019 FDA drug approvals. Nat Rev Drug Discov 19(2) 79-84.

19. Oldham P, Hall S, Burton G (2012) Synthetic biology: Mapping the Scientific landscape. PLoS One 7(4): e34368.

20. Radovan D (2019) Biosimilar development - An overview Med Writ.

21. Rahbarnia L, Farajnia S, Babaei H, Majidi J, Veisi K, et al. (2016) Evolution of phage display technology: from discovery to application. J Drug Target 25(3): 216-224.

22. Saltepe B, Kehribar EŞ, Su Yirmibeşoğlu SS, Şafak Şeker UÖ (2018) Cellular Biosensors with Engineered Genetic Circuits. ACS Sensors 3(1): 13-26.

23. Sanchez Garcia L, Martín L, Mangues R, Ferrer Miralles N, Vázquez E (2016) Recombinant pharmaceuticals from microbial cells: A 2015 update. Microb Cell Fact 15: 33.

ISSN: 2574-1241

DOI: $10.26717 /$ BJSTR.2020.29.004753

Işıl Aksan Kurnaz. Biomed J Sci \& Tech Res

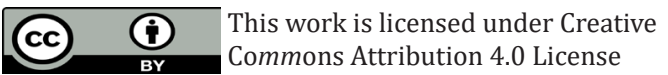

Submission Link: https://biomedres.us/submit-manuscript.php
24. Sanchez S, Demain AL (2008) Metabolic regulation and overproduction of primary metabolites. Microb Biotechnol 1(4): 283-319.

25. Sandeep V, Parveen J, Chauhan P (2016) Biobetters: the better biologics and their regulatory overview. Int J Drug Regul Aff 4(1): 13-20.

26. Sekhon B, Saluja V (2011) Biosimilars: an overview. Biosimilars 1: 1-11.

27. Sheridan C (2018) Go-ahead for first in-body CRISPR medicine testing. Nat Biotech 34: 1008

28. Sundaram PV (1996) Enzyme Engineering-Then and Now. Adv Mol Cell Biol 15: 103-115.

29. Trosset JY, Carbonell P (2015) Synthetic biology for pharmaceutical drug discovery. Drug Res Devel Ther 9: 6285-6302.

30. Verma AS, Agrahari S, Rastogi S, Singh A (2011) Biotechnology in the realm of history. J Pharm Bioallied Sci 3(3): 321-323.

31. Watson JD, Gilman M, Witkowski J, Zoller M (1992) Recombinant DNA. 2. Auflage. 626 Seiten, zahlr. Abb. und Tab. Scientific American Books, New York, USA, pp. 213.

32. Xue S, Yin J, Shao J, Yu Y, Yang L, et al. (2017) A Synthetic-BiologyInspired Therapeutic Strategy for Targeting and Treating Hepatogenous Diabetes. Mol Ther 25(2): 443-455.

33.Zeid RL (2000) Regulatory and Development Issues in the Demonstration of Therapeutic Equivalence for Multisource BiotechDerived Pharmaceuticals. Ther Innov Regul Sci 34: 919-959.

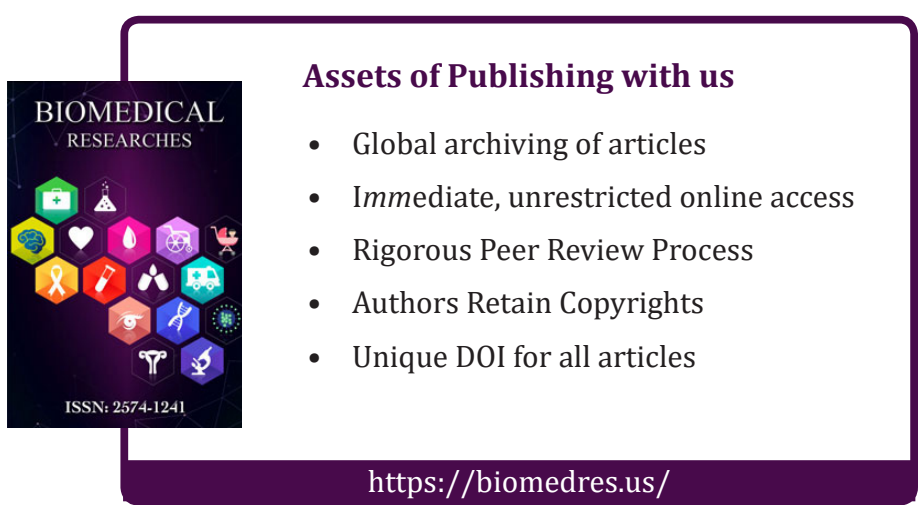

